\title{
Smart logos: a user's dashboard for the visualisation of meaningful brand experience data
}

\author{
Catarina Lelis
}

Data visualisation,

Logos have long been transporting the brand promise, which is confirmed by customisation, smartness, dynamic the carefully defined experiences the audiences have with brands. However, the new paradigms of interaction brought by social media, machine learning and big data have been shifting the power to the audiences, who are increasingly demanding less massified content and more hyper-personalised experiences. Brands have been adapting with flexible approaches, some of them made visible through their dynamic visual identities in which the logos transmogrify in some of their components, rather than being consistently static. In this research, the possibility of dynamic logos becoming smart logos - through which the brands' audiences/users can define their experiences by visualising personally meaningful brand-related data - is explored. Five creative workshops with users from three university campuses based in the United Kingdom were organised. The created outputs were analysed, and they evidence what is both considered meaningful content and the most natural logo variation mechanisms for data to be displayed and consumed. Finally, a heuristic to support the design of smart logos is proposed and the conceptual model that underpins it and that allows answering the research question is presented.

\section{Introduction}

Brands are an important intangible asset for most entities strongly relying on communication, namely due to the deep, meaningful relationships audiences can develop with a brand (Thomson, MacInnis \& Park, 2005; Schau, Muñiz \& Arnould, 2009). For years, brands have been associated with serving the purpose of distinctiveness and identification and, in fact, the benefit of enhanced brand identification is well-documented (Park, Eisingerich, Pol \& Park, 2013). Traditionally, whilst being a means for supporting identification and guaranteeing distinctiveness (Janiszewski \& Meyvis, 2001), a brand's logo has also been transporting the brand's proposition and promise to the audiences (Park et al., 2013), as is the case of Accenture's logo released in 2000, where a greater-than symbol is placed above the letter $\mathrm{T}$ highlighting the idea pointing forward to the future, whilst the lower case "a" (rather than a capitalised first letter) promises that Accenture is approachable and 
accessible (Argenti \& Druckenmiller, 2004). Such promise is very much related with the creation of meanings and experiences that brands are capable of among humans.

More than 20 years ago, Pine II and Gilmore (1998: 98) described experience as a distinct kind of economic contribution, one that would be "as real an offering as any service, good or commodity", in this way detaching the branded experience from the branded products or services. This means that the same degree of effort in developing products and designing services is put in staging experiences, which in turn seems to imply a bias toward a top-bottom control (where brands are at the top and audiences at the bottom), and where experiences become understood as orchestrated, fully programmed by the brand (Motta-Filho, 2017).

Recently, with the advent of social media and with the progressive realisation that artificial intelligence and the Internet of Things are rapidly becoming a part of our lives, there is wider acceptance that the experiences the audiences have with the brand are the holistic outcome of all the interactions with the characteristics of the interactive branded touchpoints, such as staff, products, services, environments, advertising, events, social media, etc. (Kazmierczak, 2003; Karjalainen, 2004; Zomerdijk \& Voss, 2010; Johnston \& Kong, 2011; Nysveen, Pedersen \& Skard, 2013). This leads to the acceptance that branded experiences can also be determined from a bottom-up perspective, possibly grounded on the information brands provide to their audiences and that audiences can easily access these days (Lelis, 2021), since the unprecedented access to information have made them not only more receptive to change but also more demanding.

\subsection{Dynamic Visual Identities}

According to Fournier (1998), brands are conceptual propositions and, for that reason, they need to be enacted by the branded entity to exist through a brand's identity - which should reflect and allow the systematic perception of the values of the entity in question, in a tone and style that, at best, should be unmistakable, and at the very least recognisable (Upshaw, 1995; Aaker, 1996; Malaval \& Bénaroya, 2002). It is through the brands' both tacit and explicit manifestations that the audiences can interact with the represented entity (Keller, 2013). Within the explicit manifestations, the visual identity system plays a role of utmost importance, in the sense that it determines how the brand is supposed to be represented by visual means, by setting the graphical unity through a visual code (Malaval, 2001; Malaval \& Bénaroya, 2002). As one of the most salient visual elements of a brand (Wallace, 2001), and one of the essential components of the visual identity system, the logo is also one of the most tangible manifestations of a brand's proposition and promise. 
Hence, to create a visual identity (VI), designers would usually invest a great deal of their time in its elements such as the name, the logo, the set of colours, the font, the graphical language and its applications (Mollerup, 1999; Olins, 2005; Wheeler, 2012; Van Nes, 2012), traditionally producing fixed, static forms that would crystalise one single state or condition and that can be easily regulated in brand guidelines, for consistency purposes. However, in recent years, and very much imposed by the advancements in the new screen-based technologies, there has been a shift towards more organic visual identities, where dynamic solutions seem to be of interest to not only designers and the brands, but also the brand's communities and audiences. These kinds of visual identities are recognisable for potentially allowing a new logo to be used/ displayed each day, making brands behave like living organisms (Kreutz, 2005; Felsing, 2010; Van Nes, 2012; Neumeier, 2016; Lelis \& Kreutz, 2019) and are characterised by flexibility, variability, and multiplicity of forms, usually relying on a formal genetic code used as a system of basic rules to manage the forms themselves (Guida, 2014). Van Nes (2012) proposes that rather than logos that represent a static outcome, dynamic visual identities result in holos (from holistic), since they do not intend to capture one single truth, but many - therefore opening possibilities for a multitude of stories to be told. Hence, in this case, dynamism refers to visual mutability as opposed to the traditional consistency brands' visual identities are known for.

Such a never-ending scenario of possibilities increased the levels of possible interaction that brands can have with their audiences, and such a change is an integrant element of these brands' adaptable identities - hence, it should be expressed within their visual identities, although very hard to document in a guideline format. The use of real-time data to feed several visual parameters has been explored in the context of the generation of living VIs, which adapt to reflect contextualised information. For example, Dataveyes' VI originates from the live relations between its staff members and is set in motion by their activity data (Figure 1), and Nordkyn's VI, which logo reflects the data received by a feed of Norwegian weather statistics, changes real-time when the direction of the wind or the temperature change (Figure 2). Thus, logos relying on generative systems and based on input data can be understood as a form of information visualisation (Andrzejczak \& Glinka, 2015).

It seems undeniable that dynamic visual identities resorting to generative design principles and data systems can be powerful in providing meaningful information to the audiences and, as Park, MacInnis and Priester (2006: 182) propose, brands can reduce uncertainty in individuals' lives by facilitating control in obtaining/ avoiding desirable/undesirable outcomes, "helping individuals handle daily tasks more effectively". 


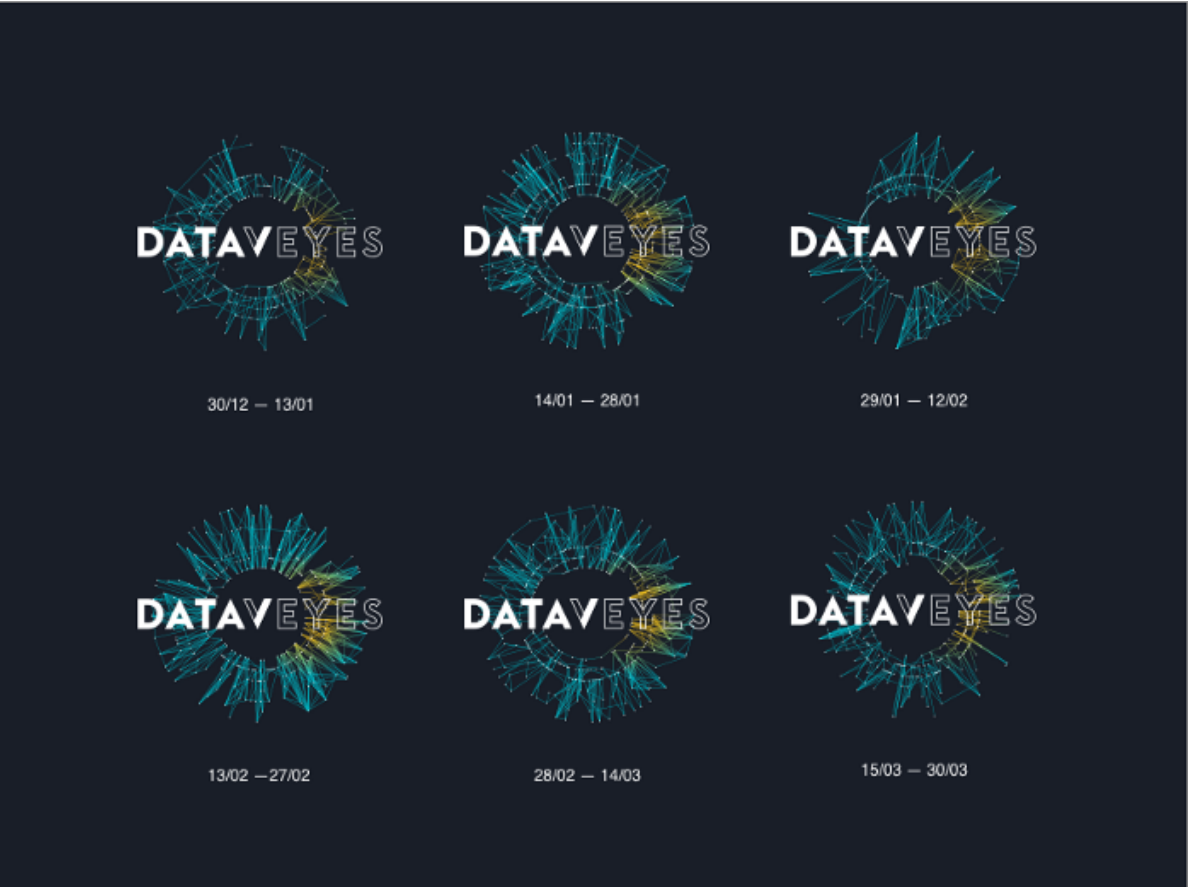

Figure 1 Computerised brand identity of Dataveyes, retrieved from Dataveyes's website. ${ }^{1}$

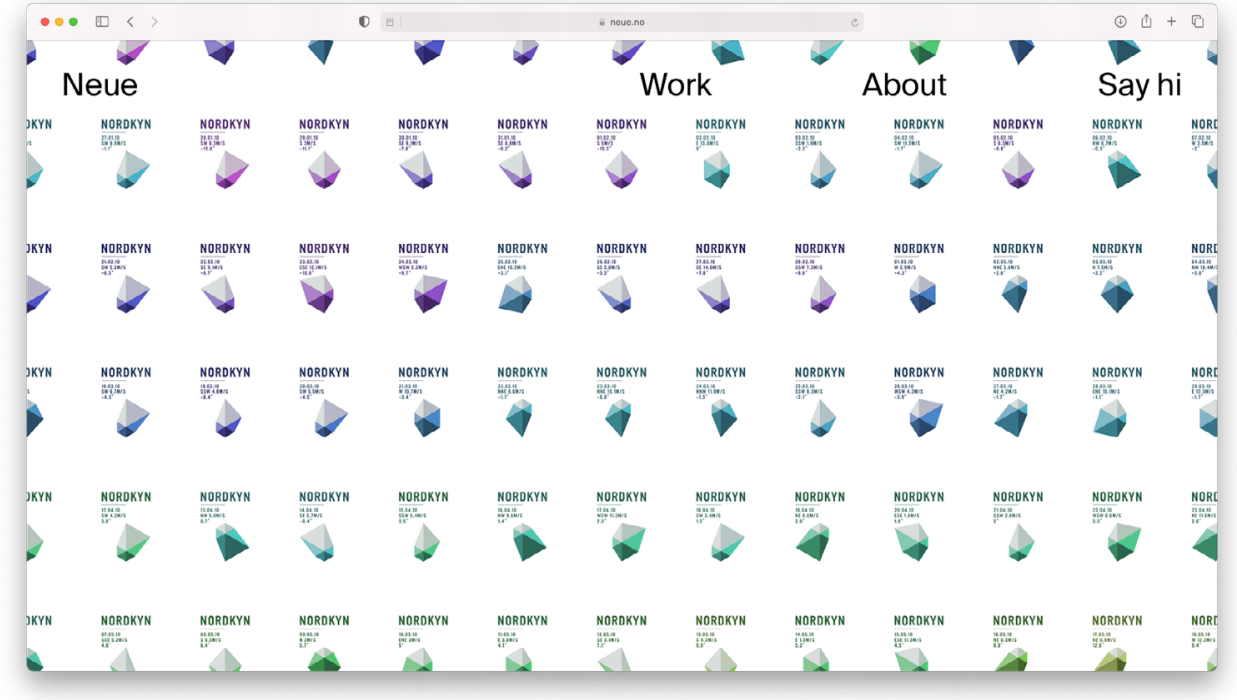

Figure 2 Computerised brand identity of Nordkyn, screen capture of Neue Studio's website. ${ }^{2}$

1 https://stories.dataveyes. com/a-new-identitybased-on-the-interactionsbetween-team-members3310dd401d 27

2 https://neue.no/work/ visit-nordkyn
Park et al. (2013) identify three mechanisms through which a brand logo creates value for its audiences: 1 ) the facilitation of self-identity/ expressiveness benefits, 2) the communication of a brand's functional benefits, and 3) the provision of aesthetic appeal. Similarly, as pointed out by Nuhoğlu-Kibar and Akkoyunlu (2017), the criteria for effective information visualisations can follow the three main components of 
the Vitruvian human-centred design principles of soundness, utility, and beauty. These are respectively related to 1) information meaningfulness (because sound infographics should communicate a message worth telling, hence providing users with something of value), 2) objectivity (since utility is measured by how the infographic supports an entity in reaching its objectives), and 3 ) design aesthetic (because it is important to find the right visual representations of the information, based on the story (Lankow, Ritchie \& Crooks, 2012), and the brand's visual identity (Figure 3).

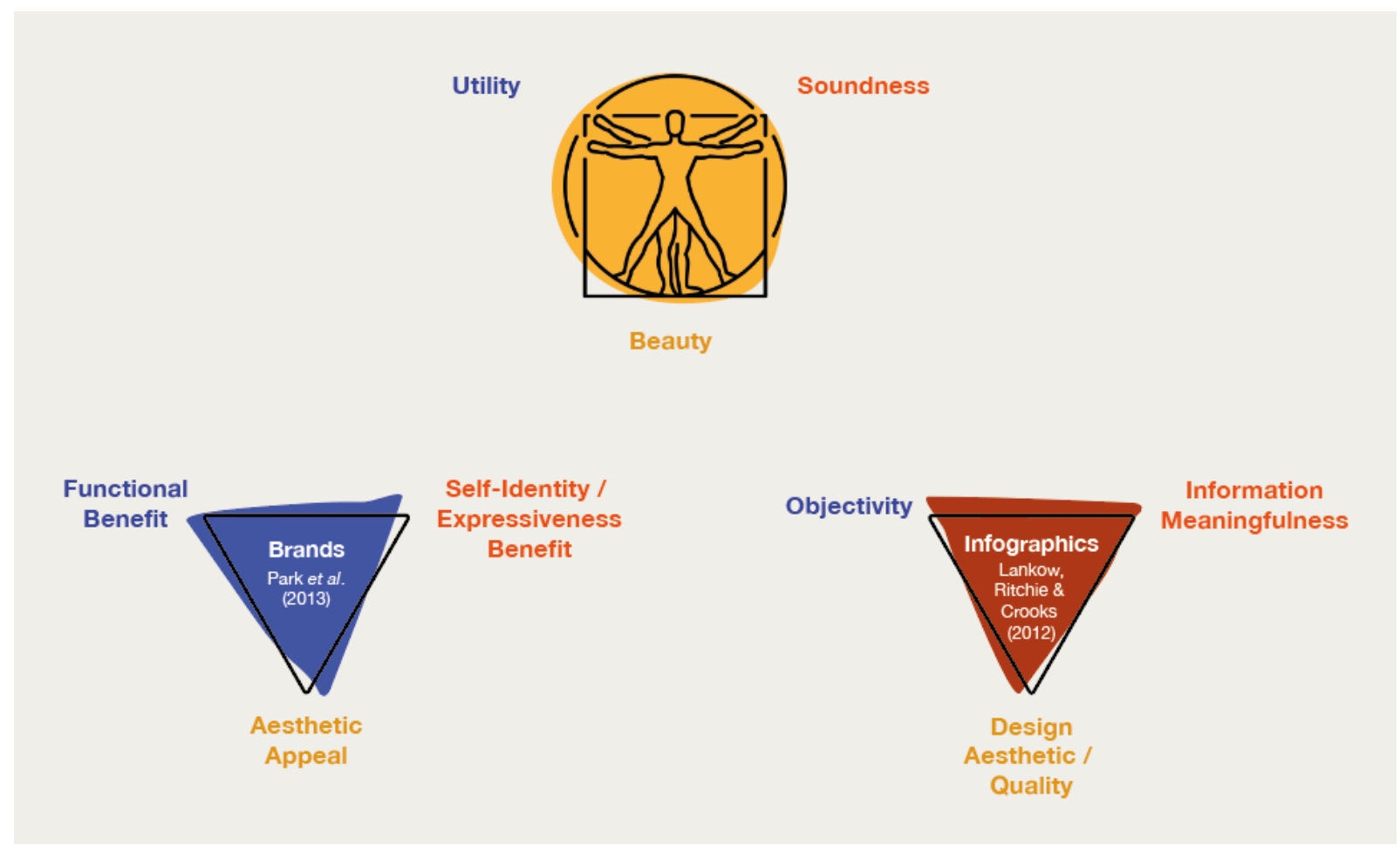

Figure 3 The correspondence between the three principles necessary for a well-designed output from three different models (Vitruvian or Human-Centred, Brands' Value Creation and Good Infographics).

\subsection{Information visualisation and storytelling}

Information visualisation communicates essential elements of complex data, ideas, or concepts by visually representing large amounts of data in simple to understand ways - information that otherwise would be considered as complex and difficult to consume (Mol, 2011; Smiciklas, 2012; Ware, 2012; Brigham, 2016; Bursi-Amba, Gaullier \& Santidrian, 2016). Also, as highlighted by Lonsdale and Lonsdale (2019: 10), visualisation can easily present the overall "shape of information and data totality within a single eye glance", which can be extremely useful for rapid decision-making, namely in scenarios of time-pressure, since visual inputs increase our capacity to process and recall information (Murray et al., 2017). 
Visualisation of information allows humans to tell a story contained within statistics documents and large amounts of text much more effectively (Lankow, Ritchie \& Crooks, 2012; Brigham, 2016). This idea of storytelling is particularly relevant for brands, which invest a great deal of their communication strategies in creating and telling stories that resonate with their audiences (Fog, Budtz \& Yakaboylu, 2005; Rodriguez, 2020). Storytelling seems to be another benefit of information visualisation since the latter is supported by the creation of a narrative grounded on data, aiming at:

... providing insight and greater understanding of the information, even bringing to the surface information that was not anticipated. Visualisation can help the user identify cause and effect relationships, classify relationships among data, identify patterns, changes or trends in data, observe developing risk threats or risk uncertainty (Lonsdale \& Lonsdale, 2019: 10).

Take Nordkyn's logo as an example, which is live data dependant, and which brand story is all about the rules imposed upon us by nature. In fact, the brand's strapline is "Where nature rules" and its logo was created to tell this story, whilst promising the current wind direction and temperature, setting out the tourists' expectations for outdoor experiences in an arctic climate characterised by extreme weather conditions.

\subsection{Logos as tiny (customisable) data dashboards}

We would argue that, in the present days, the first mechanism for brands to create value for their audiences (which coincides with information meaningfulness) is strongly associated with the possibility of customisation and the permission that brands have been recently granting their audiences to take part of both the creation of experiences and the design of their identities. For example, the case of Rio450, which involved the audiences in the creation and representational process of its visual identity through the customisation of a face-like shape, developed to celebrate the 450th anniversary of Rio de Janeiro's foundation as a city (Figure 4).

Nonetheless, despite the interesting use of data-related features that augment the possibilities of access to meaningful information by some visual identities, these lack the bottom-up perspective attached to the concept of smartness. According to Sam Palmisano, IBM's CEO from 2002 to 2012, a smart ecosystem is human-centred (Halpern, Mitchell \& Geoghegan, 2017), since it offers optimised infrastructures and customisable technology-mediated solutions, actively responding to humans' needs and big data usage, in a bottom-up approach (Giovannella, 2014). According to the ISO standards, smartness is "a quality of contributing to sustainable development and resilience, 

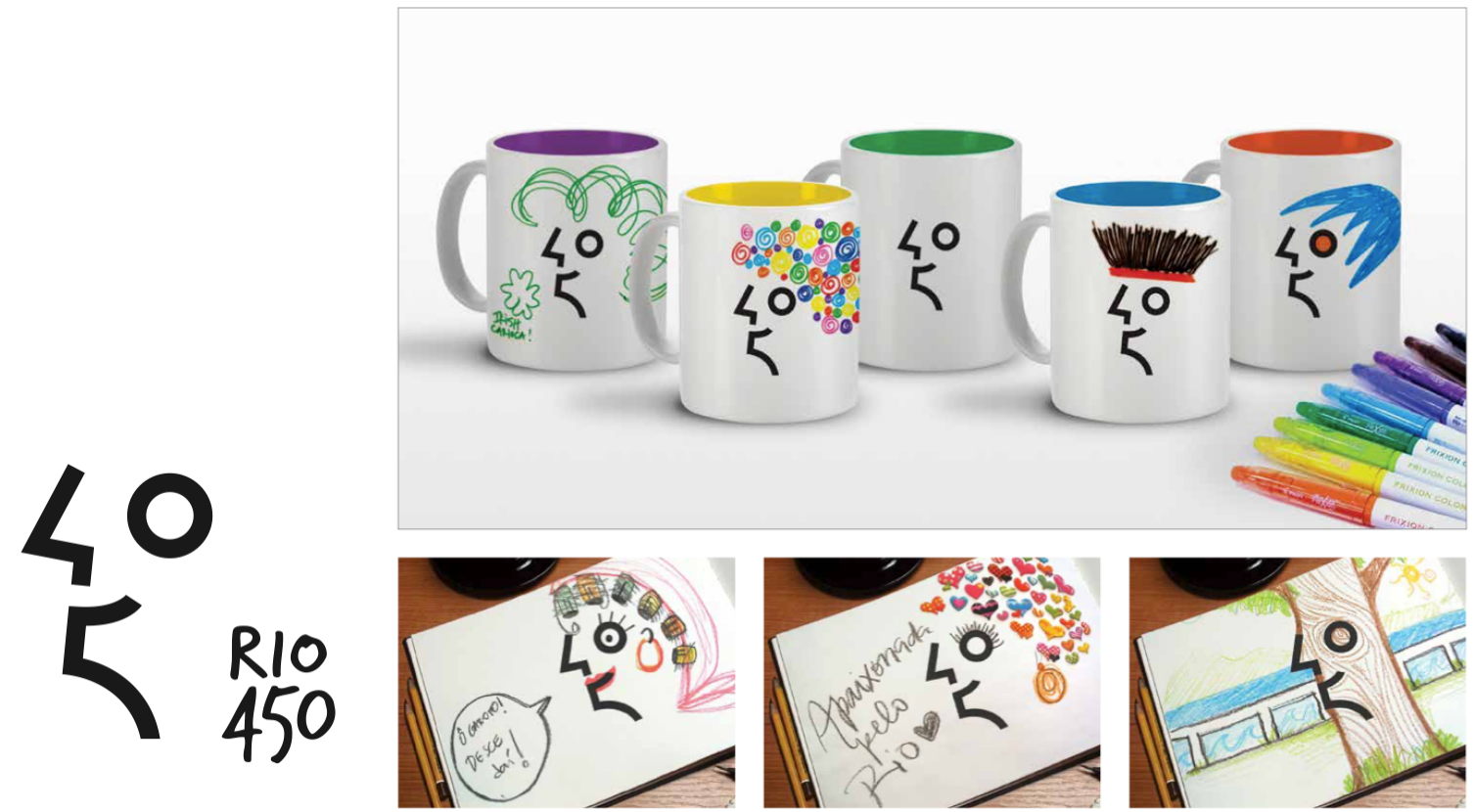

Figure 4 Customisation possibilities of Rio45o brand's visual identity.

through soundly based decision making" (ISO, 2016). Hence, smartness is a characteristic of sustainable development whilst a condition of systems in network communication that deploy datadriven analytics and algorithmic insights, allowing individuals to respond (by making necessary adjustments) to complex and dynamic circumstances (Imbar, Supangkat \& Langi, 2020) on the fly, with the purpose of optimising life.

Visual identities with such a smartness approach would configure as "smart visual identities": according to Lelis (2021), their two essential dimensions are being simultaneously Customisable (by allowing hyper-personalisation, as in the case of Rio450) and Computerised (by constantly reflecting relevant, meaningful data that contributes to optimised decision-making, as with Dataveyes and Nordkyn).

Currently, many branded entities resort to digital apps or portals as crucial touchpoints through which they establish a great deal of interaction with their audiences. Their logo is frequently used as an opening/introductory visual asset that shows for a few seconds, in a welcoming splash screen or landing page, while contents are being loaded, usually after a successful login. Besides the undiscussable and much needed/wanted function of brand identification and the interaction-related feedback (e.g. "loading, please wait"), the 1) provision of aesthetic appeal may take place, depending on the aesthetic qualities of the logo and the user's aesthetic sensitivity, the 2) communication of the brand's functional benefits (its objective utility) may be partially achieved, as it depends on the user's preexisting relationship with the brand, but surely the 3) information meaningfulness and facilitation of expressiveness benefits are 
compromised since, from an information society requirements point of view (in which smartness is increasingly relevant), the logo is useless. A holo approach - acknowledging the current human orientation toward not only receiving pertinent information, but also contributing to its co-creation - might fill this gap. In fact, according to Park et al. (2013: 186):
... managers need to consider brand logos as more effective and powerful tools in the management of customer-brand relationships than previously thought. More specifically, just because consumers can quickly identify a brand based on its logo does not mean that they will invest resources towards sustaining their relationship with the brand. That is, brand logos that are easily recognizable, yet which do not convey the brand's symbolic and functional benefits or do not provide aesthetic gratification, fail to take full advantage of their own potential.

Moreover, the possibilities for input to become visible through living logos, which adapt to different but brand-related contexts, are countless: elapsed time for an event or transport, news, activity on a site or building, number of people in a queue, store temperature, time left to hand-in rented items, among many other that can be mapped within this kind of visual resource. It is worth noting that the notion of map is of utmost relevance in this context i.e., objects of explanation about places, times, ideas and/or relationships that help us create and organise hypotheses on the world around us, but also artifacts of representation, semiotically operating as signs or signifiers. Additionally, the postmodern perspective of Deleuze and Guatarri (1987: 12) on maps has been adopted in this research:

The map is open and connectable in all of its dimensions; it is detachable, reversible, susceptible to constant modification. It can be torn, reversed, adapted to any kind of mounting, reworked by an individual, group, or social formation.

Hence, we suggest that brands, through data visualisation techniques within their logos, which is one of the components of their visual identities, may not only facilitate the identification and distinctiveness of the entity, but also serve the purpose of, within a single eye glance, mapping meaningful information, in a highly customisable way, hence allowing the audiences to tailor (to a certain degree) the experiences they want (or do not want) to have with the brand, following the premises of a smartness-informed solution. Hence, this paper advances the construct of "smart logo" (and, by inherence, "smart visual identity", which is the context in which these holos can exist), and in this study, we seek to answer the following question: What mechanisms can dynamic visual identities adopt to be considered smart visualisation instruments? 


\section{Method}

This research draws on hermeneutics and is rooted in the methodological approach of Grounded Theory, informed by inductive and abductive reasoning supporting a speculative design exercise. Being exploratory in nature, this research resorts to qualitative content analysis of artefacts that have been created at five workshops, purposely organised to capture the possible avenues for logos to be used as data visualisation devices.

After a non-probability convenience sampling method, so that participants with creative backgrounds could be selected, three workshops were delivered at the University of West London (UWL) in London, involving students of undergraduate and postgraduate (UG/PG) courses: Advertising \& PR, Graphic Design \& Illustration, Games Design, and Advertising, Branding \& Communication. The fourth workshop took place at the Manchester Metropolitan University (MMU) in Manchester, with MPhil/PhD Design students, all teaching academics. Both universities' logos include a rather simple symbolic element (alongside the lettering component). Finally, a fifth workshop (delivered remotely, during the first COVID-19 lockdown), involved a snowball sample of UG/PG students from different subject areas (Media Communication, Acting and Education) enrolled at St Mary's University (SMU), in London, an institution which VI resorts to a complex heraldic emblem.

In total 62 individuals participated in these events, in which - after being introduced to the concept of smart brand identities (Lelis, 2021) and nudged toward information visualisation characteristics - they took part of a speculative design exercise which would allow them to, individually, anticipate scenarios of meaningful campus-related data visualisation through the logos of their universities.

The collected data was analysed following an adaptation of 1) the Infographic Design Rubric (IDR) (Nuhoğlu-Kibar \& Akkoyunlu, 2017), which is comprised of two main dimensions: content generation (that corresponds to the investigative phase) and visual design generation (which corresponds to the creative phase), and 2) the Model for the Analysis of Dynamic Visual Identities (MADVI) (Martins, Cunha, Bicker \& Machado, 2019). The participants were not briefed on any of these frameworks. They were instructed that they should 1) consider their needs as a campus user, and 2) that data visualisation has usefulness, meaningfulness, and aesthetic at its core. To support the exercise, examples of different types of information visualisation were presented, along with definitions of smart campus from the literature.

Participants were then split in groups of 3-5 individuals and the first activity involved the creation of a mindmap where the central concept was "smart campus". The way the concept was to radiate and lead to new conceptual branches was left entirely to the discretion of each group. The goal was for groups to create their own understanding of a smart campus, from the perspective of the student users of such 
an environment. After that, each group had to complete a sheet listing all the data that the institution (university) holds on its students. A few hints were given, such as for them to consider the data provided for registration/enrolment, the data generated whilst being active students, and the data they might have shared in social media when tagging the university or their courses. The third activity involved filling out a sheet individually, listing all the data generated at the institution that might help users fulfil their needs as students.

Finally, on the individual speculative design exercise, participants were invited to, within their respective university's logo, create meaningful data visualisations based on what they considered relevant information (and inspired by the data they had been listing in the previous activities), should their institution adopt a smart campus philosophy. Each participant was provided with two printed outlines of their university's logo (Figure 5), along with a full spectrum of coloured markers (remote participants were also selected based on the pre-existence and availability of owned coloured markers or pencils). Hence, potentially, these workshops could result in 124 different outputs. For about 30 minutes, participants could use the logos as mapping devices to draft visualisations of data that would be meaningful to them and/or to the entire community of campus users - by surfacing the necessary data to understand, monitor and improve their lives in academia, through visual representations. They were told that, should the university develop a smart campus approach, their designs could become their own personalised app/portal's dashboard (Figure 6).

\section{Findings and Discussion}

Out of the 82 recreated logos by the workshop participants, 53 were considered valid outputs/prototypes; the remaining included no data at all or data that was not applicable or recognisable. None of the participants from SMU submitted a valid output. This could have been because their workshop ran under a completely different dynamic (via videoconference), but their comments were overall on the difficulties they were experiencing in using the intricate elements of their university's logo as containers of information.

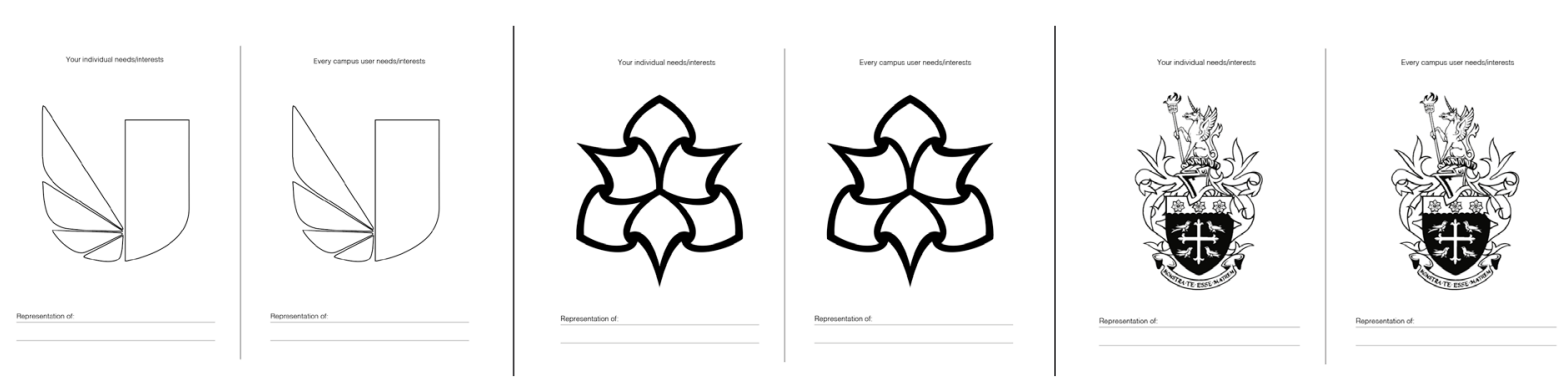

Figure 5 The three sheets with the outlined logos of each of the participating universities. 


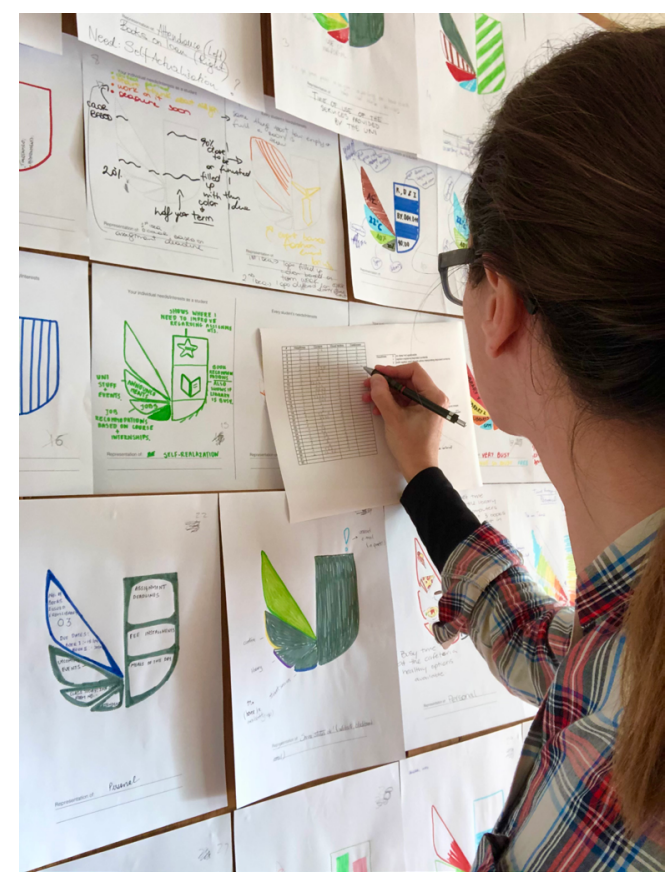

Figure 6 A sample of outputs under analysis.

The analysis of valid artefacts resorted to a codebook (Figure 7) that was split into two main anchor codes: 1) Content Generation, imported from the IDR, and 2) Logo Variation Mechanisms, brought from MADVI, with the purpose of detailing IDR's visual design generation, which in its original form entails the infographics' main features, but in this case adopting a design perspective focused on the variation possibilities of dynamic visual identities.

\section{Content generation 0 no content/ not applicable \\ Nuhoglu-Kibar \& Akkoyunlu, $2017 \quad 1$ organization of information \\ 2 mapping relationships between information components \\ 3 emphasis of essential (meaningful) information \\ 4 titles and short descriptions}

\begin{tabular}{cc|l|l}
\hline Logo variation mechanisms & 0 & no variation \\
Martins, Cunha, Bicker \& Machado, 2019 & 1 & rotation \\
& 2 & positioning \\
& 3 & scaling \\
& 4 & shape transformation/morphing \\
& 5 & colour variation \\
& 6 & combination \\
& 7 & content variation \\
& 8 & repetition
\end{tabular}

Figure 7 Codebook created to analyse the created outputs/prototypes. 


\subsection{Content Generation}

Only $28 \%$ of the outputs fulfil the four criteria of IDR's Content Generation. Nevertheless, individually, each criterion produced rather high figures:

- Organisation of information - 89\% of the designs evidence a clear concern toward organising information, using the different/independent graphical elements of the institution's logo as placeholders for data; in the case of UWL and MMU, the symbolic elements of the logos include five and six independent shapes, respectively, which resulted in most outputs having different kinds of data allocated to each shape. According to Miller (1956), five or six simultaneous features would not be problematic since nine is the upper limit for humans to process information.

- Mapping relationships between information components $54 \%$ of the outputs map relationships between different data components (e.g., between space, such as classroom location, and time-related data, such as timetabled sessions).

- Emphasis of meaningful information - 64\% emphasise meaningful information, usually basic needs and/or motivations, such as receiving optimised directions for the next meeting/class or nearest café/toilet, but also data related to achievement/success (since several instances were progression related, e.g. marks and credits accumulated), and sense of belonging and socialisation (displaying the number of country fellows simultaneously circulating on campus). This is rather relevant since visualisation design involves a series of decisions which privilege certain perspectives and show only some of the available data. These decisions are usually and primarily made by information designers, but in this case, there is evidence that the user can (and would want to) have a stance as well.

- Titles and short descriptions - 91\% of the prototyped creations included captions and short descriptions, elaborating on the visualised data, and facilitating its interpretation.

Although this research had no intention to examine participants' characteristics, it is worth noting that PhD Design students present different results from the others since $100 \%$ of their valid outputs included both detailed labels and visual hints. Some of these students wrote additional notes explaining the data flow, while detailing some possible interaction paradigms and relationships between information components. This may be due to these participants' sensitivity toward making information intelligible and accessible, a condition most likely nurtured by both their PhD candidacy and experience as design practitioners and/or lecturers. In contrast, UG/PG students' outputs are substantially more illustrative than informative, maybe because 
one of the groups at UWL's workshops had come straight from a class on Dynamic Visual Identities.

\subsection{Logo Variation Mechanisms}

The large majority of outputs resorts to two simultaneous logo variation mechanisms (coincidently most of the designs fulfilling the four criteria of Content Generation), but $8 \%$ include more than three kinds of variations.

Both Colour and Content Variation are the most popular logo variation mechanisms, in $83 \%$ and $100 \%$ of the outputs, respectively. This is not surprising since, 1 ) according to the IDR, Colour is one of the three main items under Visual Design Generation (along with text formatting and generic composition features), and 2) since logos were to be used as living, real-time data containers, the content associated to said data would necessarily have to vary in all cases. Again, PhDs seem to be the most "elastic" participants in using different features to showcase what they consider meaningful data. In fact, half of these participants' outputs include Morphing, which implicates breaking up with the graphical limits imposed by the logo's outlines in the participants' work sheets. It may also be a result of the physical characteristics of MMU's logo: six equal spade-irons positioned together, deriving from the upper part of the shield of the university's coat-of-arms (Figure 8).

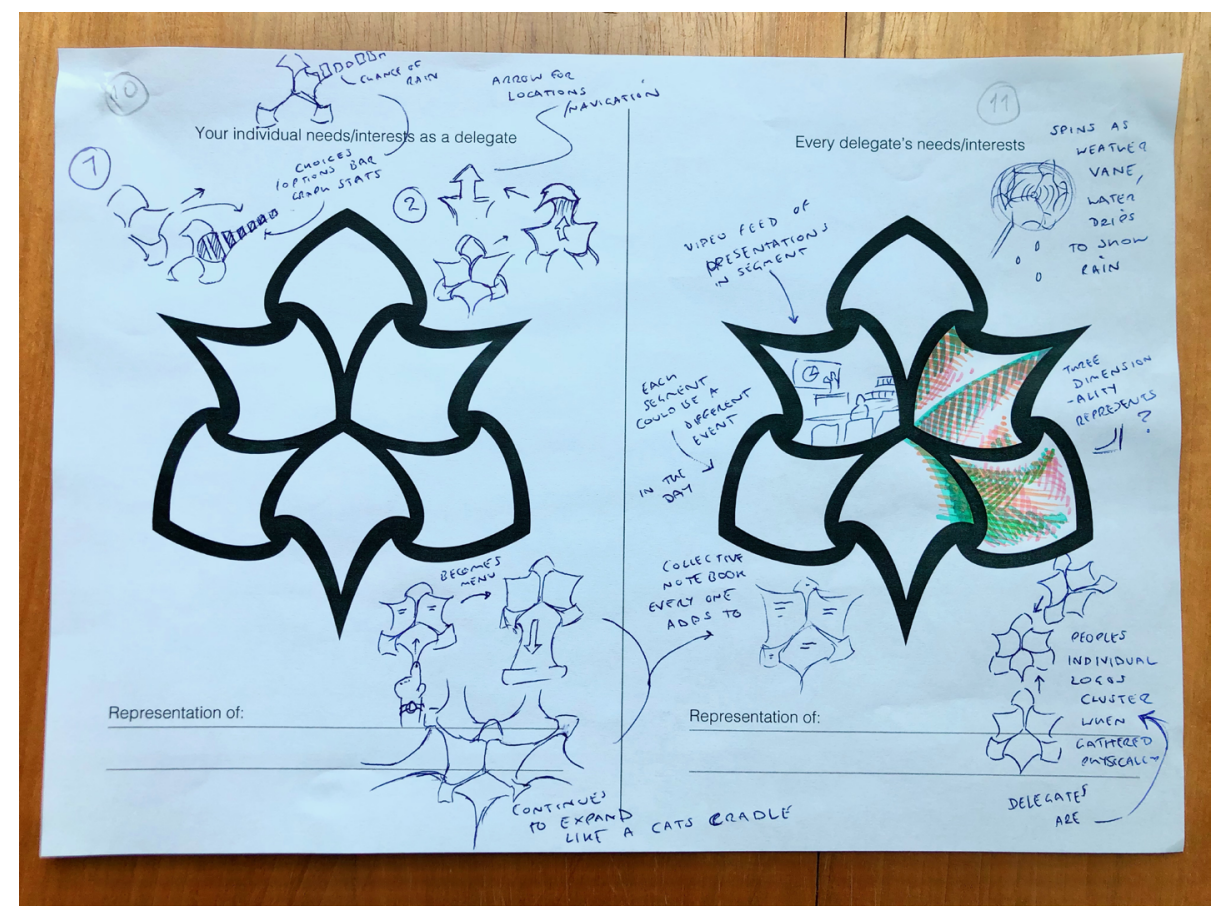

Figure 8 An example of data visualisation unfolding through logo variation mechanism Morphing. 
The less used variation mechanism is Positioning (in which a graphical element, usually from the VI, is positioned in different ways, varying in $\mathrm{x}$ and/or $\mathrm{y}$ axes); Combination (which implicates the combined use of different graphical elements that originally belong to the visual identity system) is completely absent from the analysed prototypes. We may suppose that these two variation mechanisms could somehow affect readability, an essential aspect in the context of data visualisation.

The most obvious insight from the prototypes created in these workshops is that the information such a smart approach to VI could give back to its users is, in most cases, geolocation- or time-related. In the case of the former, the logo works almost like a "within the campus compass" (leading the user to specific spaces, people, or events), in which cases the logo would adopt a flexible and movable graphical approach, likely shape-based, where Morphism, along with Colour and the unavoidable and essential Content Variation (because data is the content and it will constantly adapt to the user's needs and to the brand's context), would be a relevant mechanism.

In this sense, we call these design solutions smart logos because they can be used as explanatory visuals for exposing complex information, privileging certain (personal) viewpoints and transforming them into data aspects of users' lives that have never been datafied before (Van Dijck, 2014). Smart logos can be extended visual maps of the complexities that a customisable brand experience may entail. These logos' dynamic nature facilitates the implementation of interactive features which, according to Kennedy and Hill (2017: 771), usually "allow users to adjust the data they are shown or how it is presented”. Also, by permitting multiple outputs through (logo) instantiation, they can also configure as shared (or even co-created) storytelling assets, belonging to both the brand and the user. Figure 9 proposes a heuristic for the design of smart logos.

\section{Contribution and final considerations}

This research presents a theoretical, conceptual, and methodological contribution to the domain of data visualisation and logo design in the sense that it enhances the relevance of researching visual approaches in the field of brand communication, by 1) introducing an innovative visual creative and strategic perspective on what brands can do to further engage their audiences in authentically meaningful experiences, and 2) identifying implications for research, practice, and society. It does so by recurring to a method that differs from those retrieved in the review performed by Lonsdale \& Lonsdale (2019), where it was found that researchers often design the visualisations themselves, therefore compromising the reliability of the findings. 


\section{Heuristic for the design of Smart Logos}

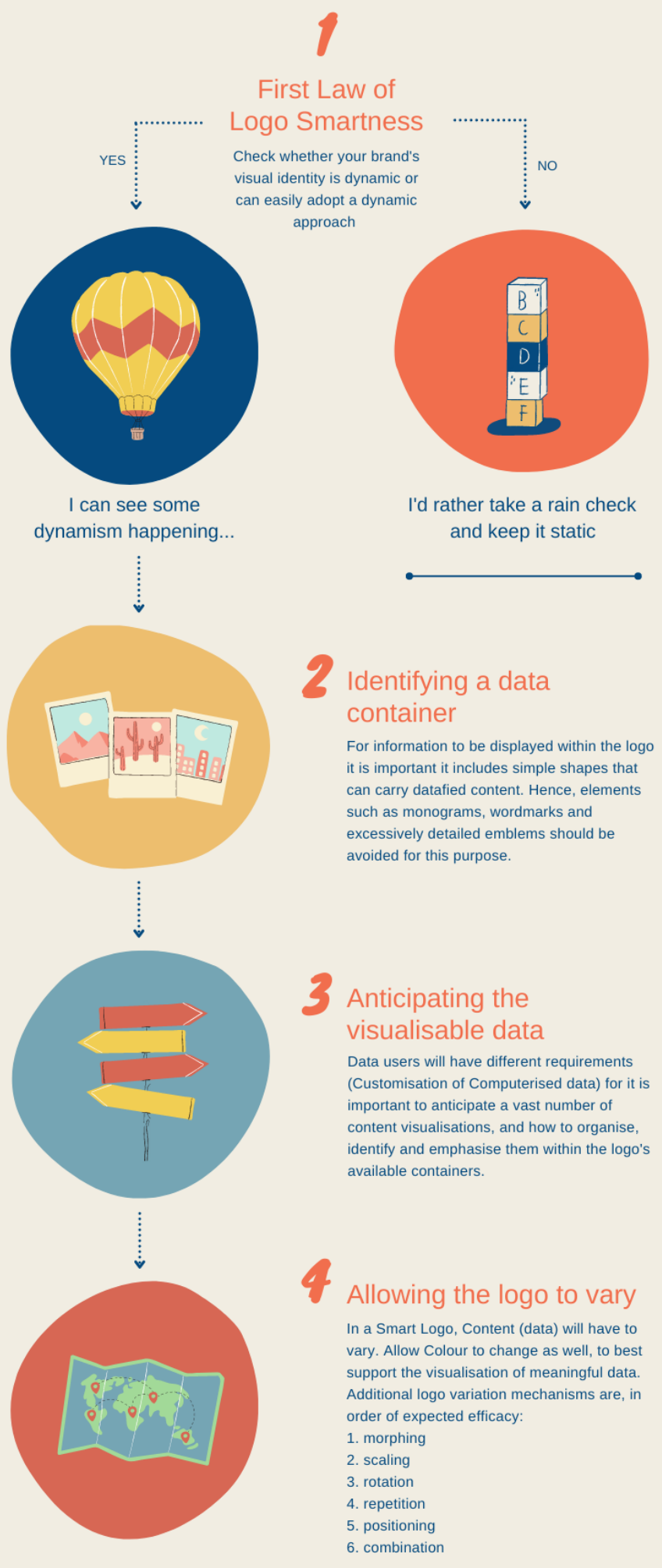

Figure 9 Heuristic for the design of Smart Logos. 
The expected outcome of this research (and answer to its research question) was, in one hand, to advance that by developing smart logos, dynamic visual identities can include useful, meaningful, and beautiful visualisation instruments. On the other hand, this research also suggests that a smart logo stemming from the principles of Computerised and Customisable dynamic VIs can enhance the experience of individuals, by using data and integrated technologies to optimise services/operations, whilst improving the quality of life of the brand's users/audiences, should these wish (Lelis, 2021).

If holos (from holistic) do not intend to capture one single truth but many, they therefore open possibilities for a multitude of stories to be told. By selecting the parameters or sets of data to be visualised, each user will potentially co-create the narrative that the brand's logo (due to being smart) can encompass. Say, for example, one of the visualisation interests of university students is around transports: if transport-related info can be displayed in the university's dashboard (in this case, its smart logo) it becomes possible for students to decide on which is the best public transport to get to the uni's shuttle and its departure stations and arrive at the intended campus on time for classes. This constitutes part of the brand experience (in its own right, a story that can be told) which the brand makes available for its users and which these customise according to their preferences and needs.

It should be highlighted that there is no intention to claim that dynamic VIs are more effective than static ones, since for some brands the dynamic visual method may not be the adequate one. It became also clear that not all VIs can straightforwardly implement such approach since their logos have not been designed to be used as maps, such as those with multiple and highly detailed shapes, as evidenced by SMU's results. In this case, it is arguable that opportunities to expand on the visual prototypes may have been constrained by the logo's characteristics, in which case the exercise was easier for some participants (UWL and MMU's) than others (SMU's). This is considered a limitation related to the institutions that accepted the challenge and that allowed the delivery of the workshop, within the delineated period for this research.

Nevertheless, it seems that smart logos may be an interesting way to achieve the three mechanisms through which a brand logo creates value for its audiences: 1 ) the facilitation of self-identity/ expressiveness benefits, due to their hyper-customisation nature, 2) the communication of a brand's functional benefits, especially for that particular user, since the brand-related data considered meaningful is being shared and made useful through computer-mediated technologies and solutions, and 3) the provision of aesthetic appeal, provided the smart logo design is sound and serious, naturally depending on the existing brand's visual identity (Figure 10). In fact, when designing a visual identity grounded on data visualisation and supported on a generative process, data can influence the design process and the way logotypes convey information (Parente, Martins \& Bicker, 2018). 


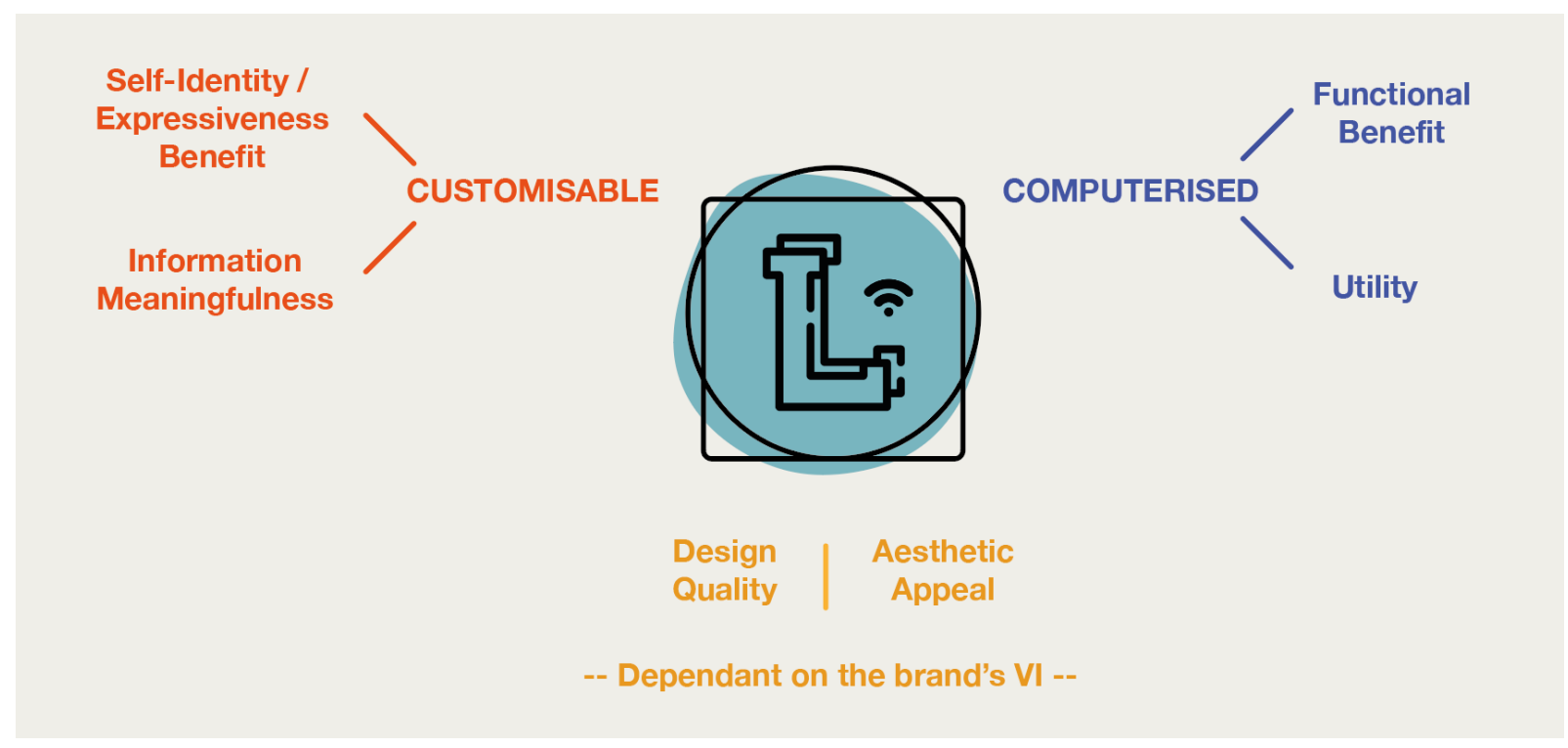

Figure 10 The principles of well-designed outputs in the context of smart logos.

For that reason, designers will want to leave as much room for dynamism as possible, while maintaining all the qualities of effective visual identities in each variation of the logo, to not compromise identification or recognition.

Future avenues of research may entail accounting for factors that determine the design process of logos as possible data dashboards, namely the users' characteristics and the context in which the data is being created, combined, and visualised. Also, it would be interesting deepening the understanding of multimodal elements, such as fonts, colours, composition/layout parameters, and their relationship with 1) how the data is perceived from a sensemaking process perspective (where visual literacy and semiotics play a huge role), 2) to what extent they contribute to the brand experience, and 3) how challenging such an approach could be in the subject area of narratology, by exploring the user experience with a brand's interactive digital narrative (since the brands' storytelling occurrences via logos' instantiation increase exponentially, as much as the possibilities of interpretation). That would require higher fidelity prototypes, likely developed (or validated) by experts in the field of data visualisation, since visually communicating data well requires skill, time, and practice. This is even more true when acknowledging that poorly designed visuals (e.g. with excessive use of typefaces, disharmonious colours, disorganised information, random use of visual elements, lack of narrative) can severely compromise the outputs (Lonsdale \& Lonsdale, 2019) and mislead the results. 


\section{References}

Aaker, D. (1996). Building Strong Brands. New York: The Free Press.

Andrzejczak, J. \& Glinka, K. (2015). Generative Visual Identity System. In New Research in Multimedia and Internet Systems, A. Zgrzywa, K. Choroś, Kazimierz \& A. Siemiński (Eds.), pp. 191-201, Berlin: Springer.

Argenti, P. \& Druckenmiller, B. (2004). Reputation and the Corporate Brand. Corporate Reputation Review 6, 368-374. https://doi.org/10.1057/palgrave. crr.1540005.

Brigham, T. J. (2016). Feast for the eyes: An introduction to data visualization. Medical Reference Services Quarterly, 35(2), pp. 215-223.

Bursi-Amba, A., Gaullier, A. \& Santidrian, M. (2016). Infographics: A toolbox for technical writers? Paris: Diderot University.

Deleuze, G. \& Guatarri, F. (1987). A thousand plateaus: capitalism and schizophrenia. London: Athlone Press.

Felsing, U. (2010). Dynamic identities in cultural and public contexts. Zurique: Lars Muller Publishers.

Fog, K., Budtz, C. \& Yakaboylu, B. (2005). Storytelling: Branding in Practice. Berlin: Springer-Verlag.

Fournier, S. (1998). Consumers and their brands: Developing relationship theory in consumer research. Journal of Consumer Research, 24, pp. 343-373.

Giovannella, C. (2014). Where's the smartness of learning in smart territories? Interaction Design and Architecture(s) Journal, 22, pp. 60-68.

Guida, F. E. (2014) Generative Visual Identities: New Scenarios in Corporate Identity. XVII Generative Art Conference, GA2014, Rome, Italy, 1619 December.

Halpern, O., Mitchell, R. \& Geoghegan, B. D. (2017). The Smartness Mandate: Notes toward a Critique, Grey Room 68(26), pp. 106-129.

Imbar, R. V., Supangkat, S. H. \& Langi, A. Z. R. (2020). Smart Campus Model: A Literature Review, 2020 International Conference on ICT for Smart Society (ICISS), Bandung, Indonesia.

ISO 37100 (2016). Sustainable development in communities - Vocabulary, December.

Janiszewski, C., \& Meyvis, T. (2001). Effects of brand logo complexity, repetition, and spacing on processing fluency and judgment. Journal of Consumer Research, 28(1), pp. 18-32.

Johnston, R., \& Kong, X. (2011). The customer experience: A road-map for improvement. Managing Service Quality, 2(1), pp. 5-24.

Karjalainen, T. M. (2004). Semantic Transformation in Design: Communicating strategic brand identity through product design references. University of Art and Design Helsinki.

Kazmierczak, E. T. (2003). Design as Meaning Making: From Making Things to the Design of Thinking. Design Issues, 19(2), pp. 45-59.

Keller, K. L. (2013). Strategic Brand Management Building, Measuring, and Managing Brand Equity (4th ed.). Harlow: Pearson.

Kennedy, H. \& Hill, R.L. (2017). The pleasure and pain of visualising data in times of data power. Television and New Media, 18(8). pp. 769-782. https://doi. org/10.1177/1527476416667823 
Kreutz,E.A. (2005). Identidade Visual Mutante: uma prática comunicacional da $M T V$. Doctoral Thesis. Porto Alegre, Brazil. Pontifícia Universidade Católica do Rio Grande do Sul.

Lankow, J., Ritchie, J., \& Crooks, R. (2012). Infographics: The power of visual storytelling. Hoboken, NJ: John Wiley \& Sons.

Lelis, C. (2021). Smart Brands and Identities: building friendly bridges between Design and Smartness, IxD\&A Interaction Design \& Architecture (s), 47, Winter 2020-21, pp. 191-214 (special issue "Pedagogical Approaches, Ludic and CoDesign Strategies \& Tools supporting Smart Learning Ecosystems and Smart Education"). Available at http://www.mifav.uniroma2.it/inevent/events/ idea2010/doc/47_9.pdf

Lelis C. \& Kreutz, E. A. (2019). Narrative dimensions supporting the visual communication of contemporary brands. Proceedings of the 1oth International Conference, Senses \& Sensibility: Lost in ( $G$ ) localization, pp. 155156, 27-29 November 2019, Lisbon, Portugal.

Lonsdale, M. \& Lonsdale, D. (2019). Information Visualisation (Design2Inform). Office of the Chief Scientific Advisor, GOV UK.

Malaval, P. (2001). Strategy and management of industrial brands: business to business products and services. Norwell MA: Kluwer Academic Publishers.

Malaval, P., \& Bénaroya, C. (2002). Aerospace marketing management. Norwell, MA: Kluwer Academic Publishers.

Martins, T., Cunha, J. M., Bicker, J. \& Machado, P. (2019). Dynamic Visual Identities: from a survey of the state-of-the-art to a model of features and mechanisms. Visible Language, 53(2), pp. 5-35.

Miller, G. A. (1956). The Magical Number Seven, Plus or Minus Two: Some Limits on Our Capacity for Processing Information. Psychological Review, 63(2), pp. 81-97.

Mol, L. (2011). The potential role for infographics in science communication. Masters Thesis, Amsterdam, The Nederlands. Vrije Universiteit Amsterdam.

Mollerup, P. (1999). Marks of Excellence: the history and taxonomy of trademarks. London: Phaidon.

Motta-Filho, M. A. (2017). Designing for Brand Experience: Operationalizing a Service Dominant Logic Approach to Branding through Service Design. Doctoral Thesis. Oslo, Norway: Oslo School of Architecture and Design.

Murray, I. R., Murray, A. D., Wordie, S. J., Oliver C. W., Murray, A. W. \& Simpson, A. H. R. W. (2017). Maximising the impact of your work using infographics. Bone and Joint Research, 6, pp. 619-620.

Neumeier, M. (2016) The Brand Flip. San Francisco, CA: New Riders.

Nuhoğlu-Kibar, P., \& Akkoyunlu, B. (2017). Fostering and assessing infographic design for learning: The development of infographic design criteria. Journal of Visual Literacy, 36(1), pp. 20-40. https://doi.org/10.1080/10511 44X.2017.1331680.

Nysveen, H., Pedersen, P. E., \& Skard, S. (2013). Brand experiences in Service Organizations: Exploring the individual Effects of Brand Experience Dimensions. Journal of Brand Management, 20(5), pp. 404-423.

Olins, W. (2005). A Marca. Lisboa: Verbo. 
Park, C. W., Eisingerich, A. B., Pol, G. \& Park, J. W. (2013). The role of brand logos in firm performance. Journal of Business Research, 66, pp. 180-187. http://dx.doi.org/10.1016/j.jbusres.2012.07.011

Park, C. W., MacInnis, D. J., \& Priester, J. (2006). Brand attachment: Construct, consequences and causes. Foundations and Trends in Marketing, 1(3), pp. 190-230.

Pine II, B. J. \& Gilmore, J. H. (1998). Welcome to the experience economy. Harvard Business Review (July-August), pp. 97-105.

Rodriguez, M. (2020). Brand Storytelling: Put Customers at the Heart of Your Brand Story. London: Kogan Page.

Schau, H. J., Muñiz, A. M., Jr., \& Arnould, E. J. (2009). How brand community practices create value. Journal of Marketing, 73, pp. 30-51.

Smiciklas, M. (2012). The power of infographics: Using pictures to communicate and connect with your audiences. Indianapolis, IN: Pearson Education, Inc.

Thomson, M., MacInnis, D. J., \& Park, C. W. (2005). The ties that bind: Measuring the strength of customers' emotional attachment to brands. Journal of Consumer Psychology, 15(1), pp. 77-91.

Upshaw, L. B. (1995). Building brand identity: a strategy for success in a hostile marketplace. New Jersey: John Wiley \& Sons, Inc.

Van Dijck, J. (2014). Datafication, dataism and dataveillance: Big Data between scientific paradigm and ideology. Surveillance \& Society, 12(2), pp. 197-208.

Van Nes, I. (2012). Dynamic Identities: How to create a living brand. Amsterdam: BIS Publishers.

Wallace, R. (2001). Proving our value: Measuring package design's return on investment. Design Management Journal, 12(3), pp. 20-27.

Ware, C. (2012). Information visualization: perception for design (3rd ed.). Waltham, MA: Morgan Kaufmann.

Wheeler, A. (2012). Design de Identidade da Marca - Guia essencial para toda a equipe de gestão de marcas (3a ed.). Porto Alegre: Bookman.

Zomerdijk, L. G. \& Voss, C. A. (2010). Service Design for Experience- Centric Services. Journal of Service Research, 13(1), pp. 67-82.

\section{About the author}

\section{Dr Catarina Lelis}

lelis@ua.pt

University of Aveiro, Campus Universitário de Santiago, Portugal

Submission date: $12 / 4 / 2021$

Approvement date: 11/11/2021 